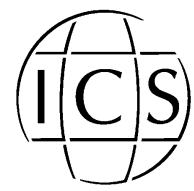

www.ics-elsevier.com

\title{
Recognition of influenza virus epitope variants by human CTL
}

\author{
G.F. Rimmelzwaan ${ }^{\mathrm{a}, *}$, A.C.M. Boon ${ }^{\mathrm{a}}$, G. de Mutsert $^{\mathrm{a}}$, \\ R.A.M. Fouchier ${ }^{\mathrm{a}}$, D. van Baarle ${ }^{\mathrm{b}}$, D.J. Smith ${ }^{\mathrm{c}, \mathrm{d}}$, \\ A.S. Lapedes ${ }^{\mathrm{d}, \mathrm{e}}$, K. Sintnicolaas ${ }^{\text {f }}$, A.D.M.E. Osterhaus ${ }^{\mathrm{a}}$ \\ a Institute of Virology, Erasmus MC, Rotterdam, Dr. Molewaterplein 50, Rotterdam 3015 GE, The Netherlands \\ ${ }^{\mathrm{b}}$ Sanquin Research at CLB, The Netherlands \\ ${ }^{\mathrm{c}}$ University of Cambridge, $U K$ \\ ${ }^{\mathrm{d}}$ Santa Fe Institute, USA \\ ${ }^{\mathrm{e}}$ Los Alamos National Laboratory, USA \\ ${ }^{\mathrm{f}}$ Sanquin Bloodbank, Rotterdam, The Netherlands
}

\begin{abstract}
Recently, an HLA-B*3501-restricted cytotoxic T-lymphocytes (CTL) epitope in the nucleoprotein $\left(\mathrm{NP}_{418-426}\right)$ of influenza A viruses was identified, which exhibited a high degree of variability. In the present study, the recognition of epitope variants by human cytotoxic Tlymphocytes (CTL) was investigated. Human CD8+ CTL clones were specific for $\mathrm{NP}_{418-426}$ epitope variants within one subtype of influenza virus or cross-reactive with hetero-subtypic variants. Positions in the 9-mer were identified as determinants of CTL-specificity. The in vivo existence of T cells cross-reactive with homo- and hetero-subtypic variants of the epitope was confirmed with virusspecific polyclonal $\mathrm{T}$ cell populations obtained from HLA-B*3501+ blood donors. Based on CTL recognition patterns and the history of infection as assessed by serology, it was hypothesized that consecutive infections with influenza viruses containing different variants of the epitope select for cross-reactive T cells in vivo. (C) 2004 Elsevier B.V. All rights reserved.
\end{abstract}

Keywords: Cytotoxic T-lymphocytes; Epitopes; Escape

\section{Introduction}

Cytotoxic T-lymphocytes (CTL) play an important role in the control of viral infections. To evade host CTL responses, some viruses accumulate mutations in, or adjacent to, CTL epitopes. Moreover, for influenza viruses, variation in CTL epitopes has been described preventing recognition by specific CTL [1]. Prolonged shedding of mutant virus in a small proportion of individuals may be sufficient to explain the rapid fixation of these epitope mutants [2]. Recently, an HLA-B*3501-restricted CTL epitope was identified

\footnotetext{
* Corresponding author. Tel.: +31-10-4088243; fax: +31-10-4089485.
}

E-mail address: g.rimmelzwaan@erasmusmc.nl (G.F. Rimmelzwaan). 
Table 1

Origin of variants of the $\mathrm{NP}_{418-426}$ epitope

\begin{tabular}{lllll}
\hline Epitope sequence & Epitope name & Period of circulation & Virus subtype & $\begin{array}{l}\text { Virus strains used in the } \\
\text { present study }\end{array}$ \\
\hline LPFDKTTIM & $\mathrm{NP}_{\text {DTI }}$ & $1977-$ present & $\mathrm{H} 1 \mathrm{~N} 1$ & $\mathrm{~A} /$ Netherlands/306/00 \\
LPFDKPTIM & $\mathrm{NP}_{\text {DPI }}$ & $1957-1972$ & $\mathrm{H} 2 \mathrm{~N} 2 / \mathrm{H} 3 \mathrm{~N} 2$ & $\mathrm{ND}$ \\
LPFDKSTIM & $\mathrm{NP}_{\text {DSI }}$ & $1972-1980$ & $\mathrm{H} 3 \mathrm{~N} 2$ & $\mathrm{~A} /$ Victoria/3/75 \\
LPFEKSTVM & $\mathrm{NP}_{\text {ESV }}$ & $1980-$ present & $\mathrm{H} 3 \mathrm{~N} 2$ & Resvir-9 \\
\hline
\end{tabular}

(LPFEKSTVM, $\mathrm{NP}_{418-426}$ ), which exhibited a high degree of amino acid variation. All variants emerged in a chronological order and replaced their ancestors. Four main variants were identified (see Table 1), which all retained their anchor residues and bound to HLAB*3501 molecules [3]. CTL raised against historic variants failed to recognize recent influenza virus strains. We decided to study the recognition of $\mathrm{NP}_{418-426}$ variants by specific CTL in more detail using tetramer staining and classical chromium release assays.

\section{Materials and methods}

Nine different CD8+ CTL clones were obtained as described previously [1]. Polyclonal $\mathrm{T}$ cell populations were obtained after stimulation of peripheral blood mononuclear cells (PBMC), with different influenza virus strains as described previously [4]. Influenza viruses A/Netherlands/306/00 (H1N1), A/Victoria/3/75 and Resvir-9 (both H3N2) were used which carry the $\mathrm{NP}_{\mathrm{DTI}}, \mathrm{NP}_{\mathrm{DSI}}$ and $\mathrm{NP}_{\mathrm{ESV}}$ variants of the $\mathrm{NP}_{418-426}$ epitope, respectively. The recognition of variants was studied in ${ }^{[51]} \mathrm{Cr}$-release assays using virus-infected or peptide-loaded EBV transformed BLCL as target cells. In addition, tetramer binding properties of CTL were studied by flow cytometry. Serum antibodies directed against historic influenza A vaccine strains were measured in a hemagglutination inhibition assay to assess the history of infection of blood donors.

\section{Results}

Four patterns of reactivity of $\mathrm{NP}_{418-426}$-specific CTL clones were observed. Five of the $\mathrm{T}$ cell clones were mono-specific for the $\mathrm{NP}_{\mathrm{ESV}}$ variant of the epitope (reaction pattern 1 , Table 2). Two $\mathrm{T}$ cell clones reacted with the $\mathrm{NP}_{\mathrm{DSI}}$ and the $\mathrm{NP}_{\mathrm{DTI}}$ variant of the epitope (reaction pattern 2). One $\mathrm{T}$ cell clone raised against $\mathrm{NP}_{\mathrm{DSI}}$ cross-reacted with the $\mathrm{NP}_{\mathrm{DTI}}$

Table 2

Cross-reactivity patterns of CD8+ $\mathrm{T}$ cell clones specific for $\mathrm{NP}_{418-426}$

\begin{tabular}{lllll}
\hline Reaction pattern & ESV & DTI & DSI & DPI \\
\hline $1\left(\mathrm{NP}_{\mathrm{ESV}}\right)^{\mathrm{a}}$ & ++++ & - & - & - \\
$2\left(\mathrm{NP}_{\mathrm{DTI}}\right)$ & - & ++++ & ++++ & - \\
$3\left(\mathrm{NP}_{\mathrm{DTI}}\right)$ & ++++ & ++++ & ++++ & ++++ \\
$4\left(\mathrm{NP}_{\mathrm{DSI}}\right)$ & - & ++++ & ++++ & ++++ \\
\hline
\end{tabular}

Recognition of individual epitopes was measured in ${ }^{[51]} \mathrm{Cr}$-release assays using virus-infected or peptide-loaded target cells and by tetramer staining; - indicates no recognition; ++++ indicates good recognition.

${ }^{\mathrm{a}}$ In between brackets, the epitope variants are indicated against which the corresponding CTL clones were raised. 
Table 3

Cross-reactivity patterns of CD8+ T cells in influenza virus-stimulated PBMC cultures

\begin{tabular}{|c|c|c|c|c|}
\hline \multirow[t]{2}{*}{ Reaction pattern } & \multicolumn{4}{|c|}{ Stimulation with Resvir-9 $\left(\mathrm{NP}_{\mathrm{ESV}}\right)$} \\
\hline & ESV & ESV/DTI & ESV/DSI & ESV/DPI \\
\hline 1 & $++++^{\mathrm{a}}$ & + & + & - \\
\hline 2 & ++++ & - & ++ & - \\
\hline \multirow[t]{3}{*}{3} & ++ & - & - & - \\
\hline & \multicolumn{4}{|c|}{ Stimulation with A/Victoria/3/75 ( $\left.\mathrm{NP}_{\mathrm{DSI}}\right)$} \\
\hline & DSI & DSI/DTI & DSI/ESV & \\
\hline 1 & +++ & ++ & + & \\
\hline 2 & +++ & - & ++ & \\
\hline \multirow[t]{3}{*}{3} & +++ & +++ & - & \\
\hline & \multicolumn{4}{|c|}{ Stimulation with A/Netherlands/306/00 (NP $\left.{ }_{\mathrm{DTI}}\right)$} \\
\hline & DTI & DTI/ESV & DTI/DSI & DTI/DPI \\
\hline 1 & ++ & + & ++ & - \\
\hline 2 & - & - & - & - \\
\hline 3 & ++++ & - & +++ & ++ \\
\hline
\end{tabular}

${ }^{\mathrm{a}}$ Indicates the relative frequency of CD8+ T cells specific for one or more epitopes.

and the $\mathrm{NP}_{\mathrm{DPI}}$ (reaction pattern 4). One of the $\mathrm{T}$ cell clones was fully cross-reactive and recognized all variants equally well (reaction pattern 3 , Table 2).

Three patterns of recognition were observed with polyclonal $\mathrm{T}$ cell populations obtained after stimulation of HLA-B*3501-positive PBMC with three different influenza A viruses containing the $\mathrm{NP}_{\mathrm{ESV}}, \mathrm{NP}_{\mathrm{DSI}}$ and the $\mathrm{NP}_{\mathrm{DTI}}$, respectively (Table 3 ). Some donors exhibited a response to all of the individual variants. A small proportion of the $\mathrm{NP}_{\mathrm{ESV}}$ specific cells, expanded after stimulation with influenza virus Resvir-9, cross-reacted with $\mathrm{NP}_{\mathrm{DTI}}$ and $\mathrm{NP}_{\mathrm{DSI}}$ (reaction pattern 1, Table 3). The $\mathrm{NP}_{\mathrm{DTI}}$-specific cells also cross-reacted

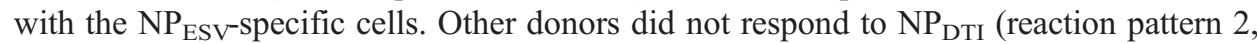
Table 3) after stimulation with an influenza A H1N1 virus and only responded to stimulation with influenza A viruses of the H3N2 subtype. In these donors, $\mathrm{NP}_{\mathrm{ESV}} / \mathrm{NP}_{\mathrm{DSI}}$ cross-reactive cells were observed, which did not react with $\mathrm{NP}_{\mathrm{DTI}}$.

The third recognition pattern revealed CTL specific for $\mathrm{NP}_{\mathrm{ESV}}$ that did not cross-react with any of the other variants and CTL specific for $\mathrm{NP}_{\mathrm{DTI}}$ that cross-reacted with $\mathrm{NP}_{\mathrm{DSI}}$. The observed reactivity of the T cells with the respective epitope variants exhibited a good correlation with the history of infection of these donors as assessed by serology (data not shown).

\section{Discussion}

In the present study, CTL were identified specific for a single variant or cross-reactive with various homo- or hetero-subtypic variants of the $\mathrm{NP}_{418-426}$ epitope. Positions 4 and 5 of the 9-mer were important determinants of T cell specificity, whereas positions 6 and 8 were not. Most of the T cells in virus-stimulated PBMC cultures were mono-specific for certain variants of the $\mathrm{NP}_{418-426}$ epitope. However, a small proportion of the CD8+ cells 
showed some degree of cross-reactivity. Some of the CTL specific for $\mathrm{NP}_{\mathrm{ESV}}$ cross-reacted with $\mathrm{NP}_{\mathrm{DTI}}$ (reaction pattern 1, Table 3 ), while other $\mathrm{NP}_{\mathrm{ESV}}$ specific cells cross-reacted with $\mathrm{NP}_{\mathrm{DSI}}$ (reaction pattern 2, Table 3). The $\mathrm{NP}_{\mathrm{DSI}^{-}}$and $\mathrm{NP}_{\mathrm{DTI}^{-}}$-specific $\mathrm{CTL}$ exhibited a high degree of cross-reactivity in some donors (reaction pattern 3, Table 3). Because the observed cross-reactivity of the CTL populations correlated with the history of infections as assessed by serology, we hypothesized that consecutive infection with viruses containing different variants of the $\mathrm{NP}_{418-426}$ epitope may expand a small proportion of CTL which cross-react with these epitope variants as has also been described in a mouse model for influenza [5].

\section{References}

[1] J.T.M. Voeten, et al., Antigenic drift in the influenza A virus (H3N2) nucleoprotein and escape from recognition by cytotoxic T lymphocytes, J. Virol. 74 (2000) 6800-6807.

[2] J. Gog, et al., Population dynamics of rapid fixation in CTL escape mutants in influenza A, Proc. Natl. Acad. Sci . U. S. A. 100 (19) (2003) 11143-11147.

[3] A.C.M. Boon, et al., Sequence variation in a newly identified HLA-B35 restricted epitope in the influenza A virus nucleoprotein associated with escape from cytotoxic T lymphocytes, J. Virol. 76 (5) (2002) 2567-2572.

[4] A.C.M. Boon, et al., The magnitude and specificity of influenza A virus-specific cytotoxic T-lymphocyte response in humans is related to HLA-A and B phenotype, J. Virol. 76 (2) (2002) 582-590.

[5] J.B. Haanen, et al., Selective expansion of cross-reactive CD8(+) memory T cells by viral variants, J. Exp. Med. 190 (1999) 1319-1328. 